\title{
Engaging Undergraduate Students in Hands-on Research Using Undergraduate- specific Small Internal Grants from the University
}

\section{Dr. Muhammad Pervej Jahan, Miami University}

Dr. Muhammad Jahan is an Assistant Professor at the Department of Mechanical and Manufacturing Engineering at Miami University. His research interests include advanced manufacturing, lean manufacturing, micro- and nano-machining, SPM-based lithography and materials. Prior to joining at Miami, he worked as Assistant Professor at Western Kentucky University and as Research Associate at the Institute for Nanoscience and Engineering at University of Arkansas. He received his BS and PhD in Mechanical Engineering from Bangladesh University of Engineering and Technology and National University of Singapore respectively. He has published more than 60 papers in refereed journals and international conferences and contributed to books, and been involved in several internal and external funded research projects in these areas. He has received numerous research awards including 'Best Paper Award - ICAMT 2016', 'Best Paper Award - ATMAE 2014', 'Outstanding Paper Award - NAMRC 2012,' 'A.M. Stickland Best Paper Award - IMechE, 2010,' and 'Most Downloaded Paper - Elsevier, 2010.'

\section{Ms. Shahnaz J. Aly, Western Kentucky University}

Shahnaz Aly, OAA, LEED AP, M. Arch, is a licensed Architect in India and Canada and Associate Professor in the School of Engineering and Applied Sciences at Western Kentucky University. She has 10 years professional experience in the architecture and construction industry in residential, commercial and mixed-use projects. She has 8 years of experience in teaching and research in areas of architectural design, sustainable design, historic preservation and BIM. 


\title{
Engaging undergraduate students in hands-on research using undergraduate-specific small internal grants from university
}

\begin{abstract}
This evidence-based practice paper aims to report last five year's experiences of both authors in engaging undergraduate students in field-specific hands-on research by utilizing small internal grants designed for undergraduate research. This study also aims to focus on how engaging in hands-on research impacted the students' learning experiences, their professional development and even their academic results and achievements. In teaching focused universities, the opportunities for undergraduate students to get involved in externally funded research are limited. However, a small grant from the universities can support involvement of both undergraduate and faculty in research activities. In the last five years, the authors have supervised more than 10 undergraduate students in the areas of architecture and manufacturing. It has been observed that engaging students in the hands-on research can greatly improve students' critical thinking. Participation in research enhances student's presentation skills by allowing them opportunities for presenting their research at regional and national conferences, as well as provides them information on the recent developments in areas of their field of study. It was also observed that students who were engaged in research with faculty often were more successful than their peers in getting job offers or admission to graduate schools of their choice. This study will discuss the university strategies and specific strategies taken by both authors to involve and enhance undergraduate students' participation in hands-on research in the areas of architecture and manufacturing. The study will also provide brief descriptions of each project including student learning outcomes and research outcomes from the project. This study aims to discuss students' professional development by comparing the students' academic achievements and professional development before and after engaging in faculty-led research projects. Finally, a section discussing possible strategies that could be taken for enhancing participation in undergraduate research at teaching focused universities will be included.
\end{abstract}

Keywords: Undergraduate research, hands-on research, undergraduate research grants, architecture, manufacturing, professional development. 


\section{Introduction}

Undergraduate research (UR) has become an integral part of the research culture at all types of universities; teaching focused universities, liberal arts colleges and major research universities. In recent years, more undergraduate students have been involved in research irrespective of their discipline; science, engineering, social science or arts. It is already a proven concept that UR can enhance the intellectual merit of students by engaging them in inquiry-based learning, prepares them for their graduate education and helps them in their professional development to enter into a career of their choice. As a result, most universities, currently are focusing on engaging more undergraduate students in research by developing innovative strategies. This study aims to discuss the experiences of both authors in engaging undergraduate students in field-specific hands-on research by utilizing small internal grants designed for undergraduate research. This study mostly focuses on the strategies of engaging undergraduate students in teaching focused university settings. The teaching focused primarily undergraduate institutes (PUI) have limited resources and funding for research compared to that of major research universities (R1). Therefore, some of the strategies may work better at the PUI setting compared to R1 setting.

\section{Literature Review}

There have been many research studies on the various aspects of undergraduate research (UR) including benefits of UR, faculty perceptions of UR, students' perceptions of UR, strategies taken by individual faculty, or discipline or even universities. Craney et al. [1] investigated the goals, advantages, and outcomes of undergraduate research spanning multiple disciplines, academic class standing, gender, and ethnicity. They conducted pre and post survey of all the undergraduate summer research participants (total 465) to understand their experience about the research and the learning goals and outcomes of their research. They were also asked to provide their demographic information including discipline, gender, previous research experience, academic class, ethnicity and so on. Most of the participants rated their research experience highly indicating that the experience helped them to learn about research and topics in depth, enriched their resume, helped them in professional development, and prepared them well for graduate school and jobs. Lapatto [2] investigated the influence of research on the educational experience of undergraduates in science by conducting an online survey from 41 institutions. It was found that $85 \%$ of the participants continued on to postgraduate education after finishing their undergraduate research. On the other hand, a small portion of the participants who didn't continue to postgraduate studies also reported comparatively poor gains from their undergraduate research experience. Learning laboratory techniques, understanding the research process and readiness for more demanding research were some of the positive effects of undergraduate research experience mentioned in the survey. Webber et al. [3] conducted a survey research by analyzing 110,000 responses to the National Survey of Student Engagement (NSSE) and 40,000 responses to the Faculty Survey of Student Engagement (FSSE) to study the importance of undergraduate research and the level of engagements from both students and faculty at the undergraduate research. It was found that the size of the institution has an impact on the involvement of undergraduates in research. Liberal arts colleges and doctoral universities were able to engage undergraduates more in research compared to research universities. In terms of faculty engagement, junior faculty and African American faculty were found to be more engaged in undergraduate research. Moreover, students with comparatively higher GPA and with a 
science background are involved in research compared to other undergraduate students. Madan and Teitge [4] presented students perceptions on the benefits of undergraduate research rather than the perceptions of faculty and administrators. According to the students who participated in this research survey, understanding the rationale behind any research study is the most important benefit of undergraduate research. Besides, one-on-one mentorship of the research supervisor is another important benefit of undergraduate research, which is otherwise difficult in undergraduate curriculum. Moreover, learning how to maintain a balance between the curriculum and research, learning about publications and professional development, developing interpersonal and communication skills are some of the major benefits of undergraduate research according to the students. In addition, developing relationship with the faculty mentor and the graduate student mentor is another positive outcome of the undergraduate research.

Haddad and Kalaani [5] presented an undergraduate research model to integrate research into a lecture- based curriculum through summer workshops, research-designated courses, and undergraduate research grants. The proposed model included establishing an Office of Undergraduate Research, developing a research-integrated curriculum, and instituting a recognition system as an incentive to encourage participation. A set of minimum requirements were set for undergraduate students participating in the research to achieve the status of undergraduate research scholar upon successful completion of the research project. Lapatto [6] investigated the reliability of undergraduate students' evaluation by conducting a survey using SURE (Survey of Undergraduate Research Experiences) and with a follow up survey after nine months. The students reported many different benefits they received from undergraduate research including readiness for graduate level research. A small group of students who discontinued their research also planned to discontinue their postgraduate studies. Other than the benefit for postgraduate studies, some others benefit of undergraduate research were independence, intrinsic motivation to learn, and active participation in courses taken after the students complete their summer undergraduate research experience. Participation in research boosts the confidence level of undergraduate students, makes them more engaged even in other coursework and also enhances leadership skills. Faurot et al. [7] analyzed the demographics and research data of undergraduate students participating in National Science Foundation funded Research Experience for Undergraduate (REU) program at a 4-year college in the Midwest funded for over 7 years. The study conducted a survey among undergraduate students to understand their perceptions on the role of graduate student mentors in the REU program. In a REU program in research universities, the undergraduate students spend more time with graduate students compared to their faculty mentor. $75 \%$ of the REU students believe they have influential relationships with their graduate student mentor in terms of academic programs and career, whereas $100 \%$ of the students believe the undergraduate research helped them to build relationships and learn more from their graduate student mentor. The findings suggest that preparing more graduate students to be mentors of undergraduate students in research could enhance the participation of undergraduates in research.

There have been studies on analyzing the faculty and student perceptions on discipline-specific undergraduate research as well as interdisciplinary research. Mabrouk and Peters [8] collected the perspectives of undergraduate students across USA and Canada to understand students' view of research. $74 \%$ of students who participated in the survey indicated that the desire to learn by own is the primary expectation of their undergraduate research experience, whereas $14 \%$ 
students indicated an interest to help others as well. 98\% students indicated that they would recommend undergraduate research to their peers and other junior students. A major portion of the participating undergraduates $(58 \%)$ indicated that faculty effort was the first thing of their interest in undergraduate research. A significant number of students $(28 \%)$ sought out the opportunity by themselves. Less than half of the students (33\%) spent about two years for their undergraduate research, whereas majority of the students spent less than a year. Majority of students $(58 \%)$ were supported during their undergraduate research and the faculty mentor was responsible for their daily guidance. Oliveria et al. [9] conducted a cross-sectional survey among $1^{\text {st }}$ to $6^{\text {th }}$ years medical students from an established medical school to learn about the levels of their engagement at undergraduate research, their challenges and motivation for undergraduate research, and how they benefited from undergraduate research. Based on the students' perception, time constraint was the major obstacle for undergraduate research. About $47 \%$ of the students were involved in undergraduate research, and the percentage of participation in research increases from $1^{\text {st }}$ to $6^{\text {th }}$ year. The students who didn't participate in research favored the inclusion of research in undergraduate curriculum. Moreover, most of the students agreed, even those who quit research at some point, that they would recommend undergraduate research to future students as it better prepared them for internship and residency.

In addition to discipline - specific studies, previous research has focused on engaging undergraduate students in interdisciplinary research on cutting edge research areas spanning nanotechnology, and integrating computer science with medical technology. Goonewardene et al. [10] discussed the strategies taken by a small public university to engage undergraduate students in research through interdisciplinary research in nanotechnology. It was reported that the novelty of nanotechnology and its growing career potential were able to attract a talented pool of undergraduate students at freshmen and sophomore levels. It was reported that publications in peer-reviewed journals has significantly increased as a result of this, and there was no negative impact on the students' GPA due to their participation in research. Moreover, engaging in research early in their career helped retain students in STEM fields by motivating them about science and nanotechnology, as well as helped in the professional development of students. Raicu and Furst [11] proposed a model based on NSF-REU to enhance the participation of undergraduate in interdisciplinary research spanning computer science with medical science. The data received from the outcome of the model after three years indicate that interdisciplinary approach increased the participation of undergraduates in research and also was able to attract a talented pool of students from multiple disciplines. They analyzed demographics, profiles and outcomes of 26 undergraduate students working on a total of 17 interdisciplinary projects. The proposed model was successful to generate 16 conference papers, 1 journal paper, 9 extended abstracts and posters by engaging undergraduate students in interdisciplinary research.

There have been several research studies that focused on the strategies taken by universities, both major research universities and small liberal arts colleges. Leverson [12] discussed the approaches taken by Florida State University (FSU) office of research to enhance participation of undergraduates in Arts and Humanities research. An ad hoc committee from the office of research conducted a survey among faculty and administrators. The survey reveals the importance and interests of undergraduate research and identified several important factors to enhance participation. The need for more support, enhancing the visibility of faculty working with undergraduates, and expanding the scope of work were found to be important to enhance 
undergraduate participation. In order to enhance the participation of undergraduate students, various strategies were proposed such as introductory workshops, classes, funding mechanisms, and opportunities for presentation of research and creative works. Gonzalez [13] presented the strategies taken by University of California, Davis to enhance the participation of undergraduates in research. Some of the key strategies include an annual undergraduate research symposium, an undergraduate research journal, two newly developed undergraduate research programs; the federally funded AGEP (Alliance for Graduate Education and the Professoriate) and the University of California system-sponsored UC LEADS (University of California Leadership Excellence Through Advanced Degrees). There are also existing undergraduate research programs including McNair Scholars Program, the President's Undergraduate Fellowships, and the Summer Honors Advanced Research Program, to name a few. They also discussed the research goals and differences in strategies for research at five different levels: lower division, upper division, masters, doctoral, and postdoctoral. Hoke and Gentile [14] discussed the financial support and strategies taken by University of Richmond, a private liberal arts college, to engage undergraduate students in research in their freshmen and sophomore levels, the challenges faced in the process, and the success measures. It was reported that early engagement of undergraduates in research in the STEM field is possible and has several advantages including increased retention rate. It was also reported that the success of early involvement of undergraduates requires funding, close faculty mentoring, and programmatic features to address each student's level of coursework. It was also mentioned that the internal grants from universities played an important role in enhancing the early involvement of undergraduates in STEM research. The major challenge faced was the lack of background knowledge of the research projects from coursework, which can be overcome by the mentor teaching the background knowledge. The early involvement was successful in keeping many of the students in research for 4 years of their undergraduate study, and even in placing them for $\mathrm{PhD}$ or $\mathrm{MD} / \mathrm{PhD}$ programs.

It can be seen from the extensive literature review that undergraduate research is an integral component of undergraduate education and their professional development. Therefore, many researchers have presented their experiences as well as students' perceptions of the benefits of undergraduate research. This paper highlights the strategies taken by two teaching focused universities for improving the engagement of undergraduate research and its impact on the students' professional development. The strategies and outcome presented in this paper may be applicable to similar teaching-focused universities, commonly known as PUI.

\section{Methodology}

\section{Research question, sample, and procedure of data collection}

The research question for this paper is "How can small grants from the university have an impact on professional development of undergraduate students by engaging them in research?" This study aims to collect and analyze students' demographic data, research and learning outcomes, and professional development of undergraduate students from authors' current and past research projects that were funded by the universities. The data presented in this study has been collected from a total of 13 research projects in the fields of architecture and manufacturing. Both current and past research projects have been included to reflect on if undergraduate research (UR) 
encouraged them in future research opportunities, whether UR encouraged them to enter into graduate schools, or UR impacted their professional development. All the data presented for each project including students current position has been tracked over time and collected by the authors. Student demographic data has been presented in the study to see if there is any effect of gender, students' academic year, GPA, immigration status, on their willingness to be engaged in research during their undergraduate study.

\section{Description of the programs}

This study included undergraduate research projects that have been funded internally by the university using a small grant. A total of 13 research projects have been included in the analysis, which include both current and previous projects of two authors in the areas of Architecture and Manufacturing. The projects were supported by small internal grants $(\$ 500-\$ 3000)$ at two universities. Although small, those grants are competitive and research proposals need to be submitted to receive those grants. The brief description of two types of such grants from two universities are presented below.

"Faculty-Undergraduate Student Engagement (FUSE) grants at Western Kentucky University (WKU) are designed to support undergraduate students' intellectual development by fostering active engagement in the areas of research, creative and scholarly activities, and/or artistic performances [15]." The grants are competitive and available to students at the sophomore level and beyond. They are awarded during the Fall and Spring semesters each year. Students are expected to work under the guidance of a faculty mentor to conduct research in the desired topic area. The application consists of a one-page narrative which outlines the objectives, the methodology, expected results, significance and product of the research and a budget narrative. Students are also expected to describe their professional aspirations. The faculty mentor has to attest to the student's ability to undertake and complete the research. The application is a twostep process; from student to faculty mentor and from the faculty mentor to the Office of Sponsored Programs. The grant award consists of $\$ 3000$ which could be used for research related expenses, students and faculty travel to present at conferences. Additionally, the student receives $\$ 500$ upon successful completion of the project and the faculty mentor receives $\$ 500$ for professional development in addition to $\$ 500$ being given to the faculty's department to incentivize student-faculty research. The research takes place under the umbrella of a one-hour research course "UC 400: Mentored Research Experience". One of the expectations of the FUSE grant is a presentation at a national or regional conference, as well as a poster/presentation at WKU's annual research week. The faculty is expected to submit publication(s) upon completion of the grant. [15]

“The Undergraduate Research Award (URA) program at Miami University encourages students to seek out a faculty-mentored experience in developing a research grant proposal [16]". The grant amount varies between ( $\$ 150$ to $\$ 500$ ), which are supposed to be spent for research expenses, i.e. purchasing supplies and materials for research. All enrolled full-time undergraduate students in all disciplines on all campuses who have a GPA of at least 2.0 are eligible to apply. The student should approach a faculty member and write the proposal in accordance with the faculty and submit with faculty member's review and signature. Usually, the 
students are given one to two semester(s) to complete the research project and submit the final report including any presentation or publication generated from the research.

\section{Analysis of data}

A total of 13 research projects have been included in this study. Information about students' demographics (gender, immigration status, i.e. domestic/foreign student, US citizen or not) and academic background (major, college year, GPA, attending graduate school or not) as well as information about research outcome (presentation at national or regional conference, publications in conference, journal article, or book chapter etc.) have been included in this paper. The analysis was done to answer the following questions:

(a) Does the gender or immigration status have any relation with the participation of undergraduates in research?

(b) Can the college year and GPA be an indicator of students' interests in UR?

(c) Is there any trend in future career focus for students who engage in UR?

(d) Does participating in UR help in their professional development?

(e) What kind of research expectation(s) are logical as an outcome from small research grants for a period of a semester to a year?

(f) Does UR promote faculty development as well in teaching - focused universities?

\section{Results}

Results of the 13 projects undertaken by faculty are presented in the table 1 provided in the appendix.

Table 1: Summary of the undergraduate research projects with students' demographics, academic profile, project status, and research outcome

[See Appendix]

\section{Summary of Table 1}

Table 1 presents the summary of a total of 13 funded research projects that were carried out by the authors. Out of the 13 projects, 9 were in the areas of "Advanced Manufacturing" and 4 were in the area of "Architectural Sciences". Most of the projects were carried out between Fall 2012 to Fall 2017, and 4 projects are currently in progress. Among 13 students, 4 students were female students and only 1 was an international student. At the time of applying for research grant, 8 students had above 3.5 average GPA and rest had GPA between 3 to 3.5. The projects generated a total of 1 book chapter, 3 journal articles, 4 conference proceedings paper, and multiple presentations in national and regional conferences. The students also won "Best Paper Award" and "Best presenter" awards as a result of those undergraduate-specific mini research grants. The students also benefitted by learning hands-on and soft skills that helped them in their professional development.

\section{Discussion}


From the table 1 presented in the appendix, one can see the scope of the projects undertaken by undergraduate students under the mentorship of the authors in the areas of architecture and manufacturing. The table only highlights the funded projects that were completed or are in progress. In addition, there were a number of students who applied for UR grants under the mentorship of the authors but were unfunded due to the competitive nature of the grants. Of the 13 projects undertaken, 4 of them included female students while the majority of the participating students were male students. Only 1 of the female student was in manufacturing, whereas 3 of them conducted research in architecture. Both programs have a greater male student population to female student population in the classroom which indicates the greater number of male students involved in UR research than female students. In terms of the influence of immigration status on students' involvement in UR, it was found that only 2 projects were carried out by international students, whereas, most were domestic students. There may be two reasons for this fewer engagement of international students in undergraduate research. First, the architectural science and manufacturing engineering programs at the universities have a small international student population at the undergraduate level, hence the lower rate of international students involved in UR. Another reason may be comparatively lesser involvement of international students in extra-curricular activities.

In terms of the influence of GPA, table 1 shows that all 13 students had a GPA of greater than $3.0,8$ of these students had a GPA of greater than 3.5 at the time of their research projects. One primary reason for comparatively higher GPA of students engaging in UR is the requirement set by the universities. For example, at WKU the minimum GPA required was 3.0 or above while at Miami University the minimum required GPA was 2.0 for application for the UR grants. Another reason may be the fact that the students with higher GPA are more interested in engaging themselves in the UR and approach faculty more to show their interests.

One important observation is that the research productivity and outcome of the projects depend on the academic standing/year of students. Of the 13 students discussed in this paper 2 were seniors, 10 juniors, and 1 was a high school student. The juniors and high school student had stronger research outcomes; presentation at more than one conference and published paper. On the other hand, the senior students did not have as strong research outcomes with one student presenting at only one conference while the other student did not present at all. This could be an indicator of the fact that students who are juniors or lower have at least 2 years left in university from the start of their research projects which give them substantial amount of time to take their projects to a logical conclusion. On the other hand, while senior students may be involved in their projects they have about a year or less to complete and present their project which makes it a difficult timeline to complete research expectations. This finding clearly suggests involvement of students in UR should begin as early as in their sophomore/junior year.

Many of the students who completed UR projects and had graduated had gone onto graduate school. The table 1 shows that 5 students were either in graduate school or had completed graduate school. There were two students who were to start graduate school in Fall 2018. All of the students who had graduated had secured a job in industry.

Benefits of the UR projects were innumerable. Except for one student who had not presented his project, all students had presented their projects at either national or regional conferences which 
helped them gain experience in creating professional presentations and gain confidence in public speaking in a professional setting. Many of them had co-authored a conference proceeding paper or a journal article with their faculty mentor. This enabled them to get exposure to literature review and professional writing standards. This also was an advantage while applying to graduate schools. The students learned a number of new skills and advanced some of their basic skills; for example, manufacturing students learned to operate CNC micro-machines and optical microscopy techniques, while architectural science students learned how to operate a 3D printer and advanced digital modelling techniques. Students were able to work with state-of-the-art equipment and new technologies. They learned how to design experiments, gather and interpret data. All of these advantages went beyond regular opportunities available in the classroom.

While the table 1 does not focus on benefits of UR research to faculty, there are a number of benefits of the UR experience for faculty. Faculty are able to use results from these projects in the classroom. In one of the projects where the student worked on 3D printing, the faculty extended the use of 3D printing in a design studio project. Faculty are also able to present results in the classroom to strengthen their lectures. In terms of research, faculty are able to use these projects as part of larger research initiatives or as a pilot project for expanding their research and applying for larger internal and external grants. Some of the grants also provide funding for faculty to accompany the student to conferences which contribute towards their professional development. The FUSE grant at WKU and USS grant at Miami University provide faculty with funds for professional development which is an added incentive.

\section{Conclusion}

This study presented how undergraduate students could be involved in research by internally funded small research grants from the universities. Based on the outcome of 13 undergraduate research projects, this study also investigated how UR was helpful in the professional and career development of undergraduate students. The following conclusions have been drawn from this evidence-based practice study:

- In terms of demographics of the students, more male and domestic students were involved in UR in STEM fields. However, more female students were engaged in the UR within the Architecture discipline. The students with higher GPA were more involved in the UR for both Architecture and Manufacturing discipline.

- The earlier the undergraduate students get involved in UR, the better the research outcome and productivity of the students. Students joining research projects as juniors have higher take away from the research compared to those joined as seniors. Students who conducted research as juniors were able to publish in peer-reviewed journals and conference articles even before completing their undergraduate degree.

- There is a trend between the research productivity and interest for graduate school. It was found that a majority of the undergraduate students who participated in UR, went onto graduate school to engage themselves in further research. Students with better research productivity showed higher interests for graduate school.

- Some other benefits of UR are found to be better operating skills of the equipment and machine tools, better understanding of technical and professional writing, better interpersonal and public speaking skills and so on. Those interpersonal and professional 
skills better prepare them for industry jobs. All the students participating in UR were more successful in job searches as compared to their peers.

- Faculty also benefitted from UR, especially with more teaching loads at primarily undergraduate institutes. The findings from this study suggests that both faculty and students can be benefitted by engaging undergraduate students early in their college career and engaging them longer in the project.

- Finally, this study shows that small internal grants focusing on undergraduate research from teaching focused universities were successful in engaging more undergraduates in research, which helps in the professional development of both students and faculty.

\section{References}

1 C. Craney, T. McKay, A. Mazzeo, J. Morris, C. Prigodich, R. D. Groot, "CrossDiscipline Perceptions of the Undergraduate Research Experience", The Journal of Higher Education, Vol. 82, No. 1, pp. 92 - 113, January/February 2011.

2 D. Lopatto, "Survey of Undergraduate Research Experiences (SURE): First Findings", Cell Biology Education, Vol. 3, 270-277, Winter 2004.

3 K. L. Webber, T. F. N. Laird, A. M. BrckaLorenz, "Student and Faculty Member Engagement in Undergraduate Research", Research in Higher Education, Vol. 54, Issue 2, pp 227-249, March 2013.

4 C. R. Madan, B. D. Teitge, "The benefits of undergraduate research: The student's perspective". The Mentor: An Academic Advising Journal, May 1, 2013. Available: http://dus.psu.edu/mentor/. [Accessed February 4, 2018].

5 R. J. Haddad, Y. Kalaani, "Undergraduate Research Scholar: The First Step towards a Hybrid Lecture-Based and Inquiry/Research-Based Engineering Program”, Technology Interface International Journal, Vol. 15, No. 2, pp. 36 - 41, Spring/Summer 2015.

6 D. Lopatto, "Undergraduate Research Experiences Support Science Career Decisions and Active Learning", CBE-Life Sciences Education, Vol. 6, 297-306, Winter 2007.

7 M. E. Faurot, F. Doe, E. R. Jacobs, N. G. Lederman, E. M. Brey, "From the Undergraduate Student Perspective: The Role of Graduate Students in an Undergraduate Research Program", Proceedings of $120^{\text {th }}$ ASEE Annual Conference and Exposition, June 23 - 26, 2013, Atlanta, Georgia.

8 P. A. Mabrouk and K. Peters, "Student Perspectives on Undergraduate Research (UR) Experiences in Chemistry and Biology", Council on Undergraduate Research, pp. 25 32, September 2000.

9 C. C. Oliveira, R. C. deSouza, É. H. Sassaki Abe, L. E. Silva Móz, L. R. de Carvalho, and M. A. C. Domingues, "Undergraduate research in medical education: a descriptive study of students' views", BMC Medical Education 2013, 14:51.

10 A.U. Goonewardene, C. Offutt, J. Whitling, D. Woodhouse, "Engaging Undergraduates through Interdisciplinary Research in Nanotechnology", Journal of College Science Teaching, Vol. 41, No. 3, pp. 36-41, January 2012.

11 D. S. Raicu, J. D. Furst, "Enhancing undergraduate education: a REU model for interdisciplinary research", Proceedings of the 40th ACM technical symposium on Computer science education, Pages 468-472, Chattanooga, TN, USA — March 04 - 07 , 2009. 
12 C. W. Levenson, "Enhancing Undergraduate Research in the Arts and the Humanities", Peer Review, Vol. 12, No. 2, pp. 13 - 15, Spring 2010.

13 C. Gonzalez, "Undergraduate Research, Graduate Mentoring, and the University's Mission", Science, 293, 1624, 2001.

14 K. Hoke, L. Gentile, "Early Involvement in Undergraduate Research at the University of Richmond", CURFocus, Vol. 29, No. 1, pp. 18 - 23, FALL 2008.

15 https://www.wku.edu/research/fuse.php

$16 \mathrm{https} / / /$ miamioh.edu/research/student-research/project-funding/ura/index.html

\section{Appendix}

Table 1: Summary of the undergraduate research projects with students' demographics, academic profile, project status, and research outcome 


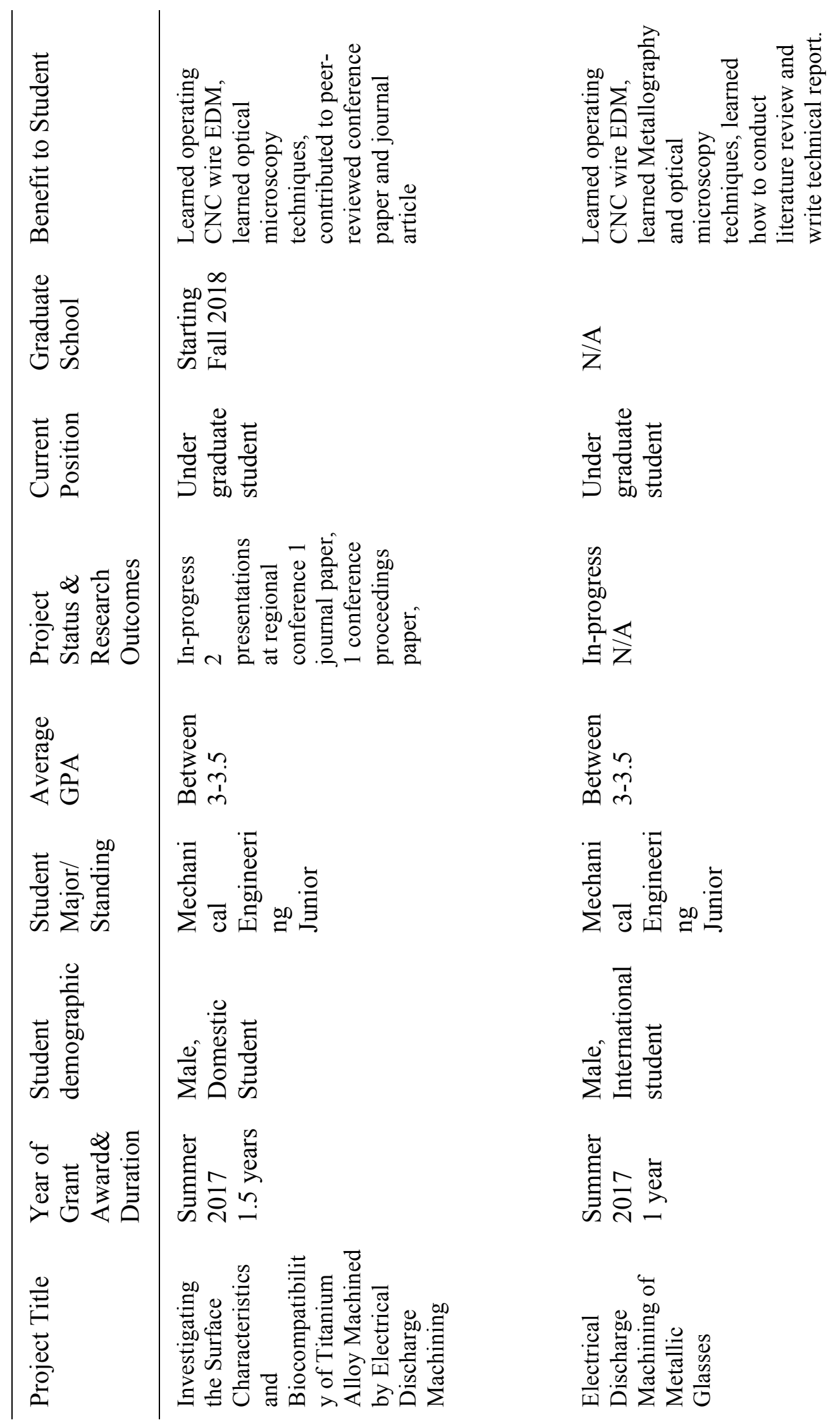




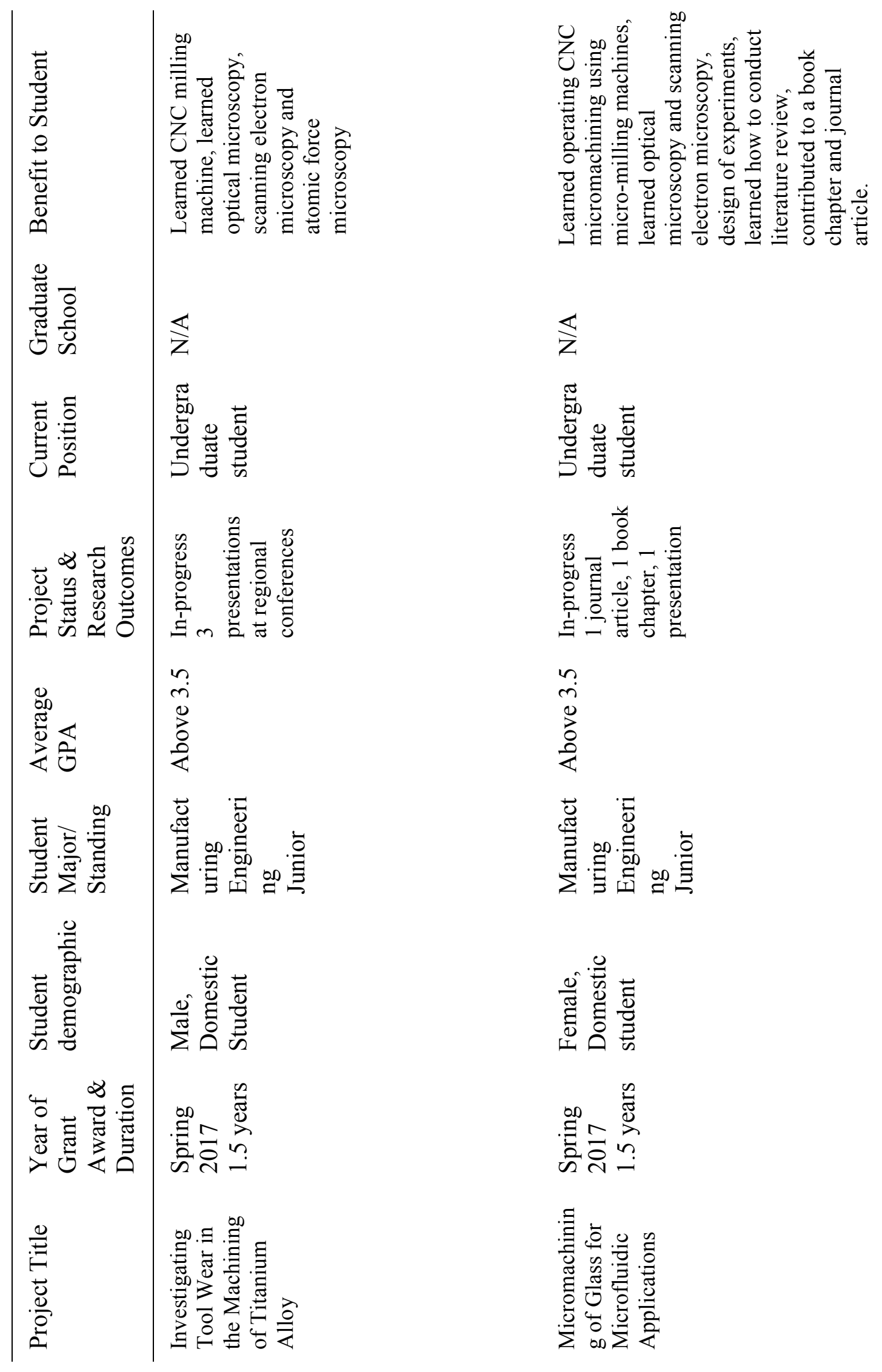




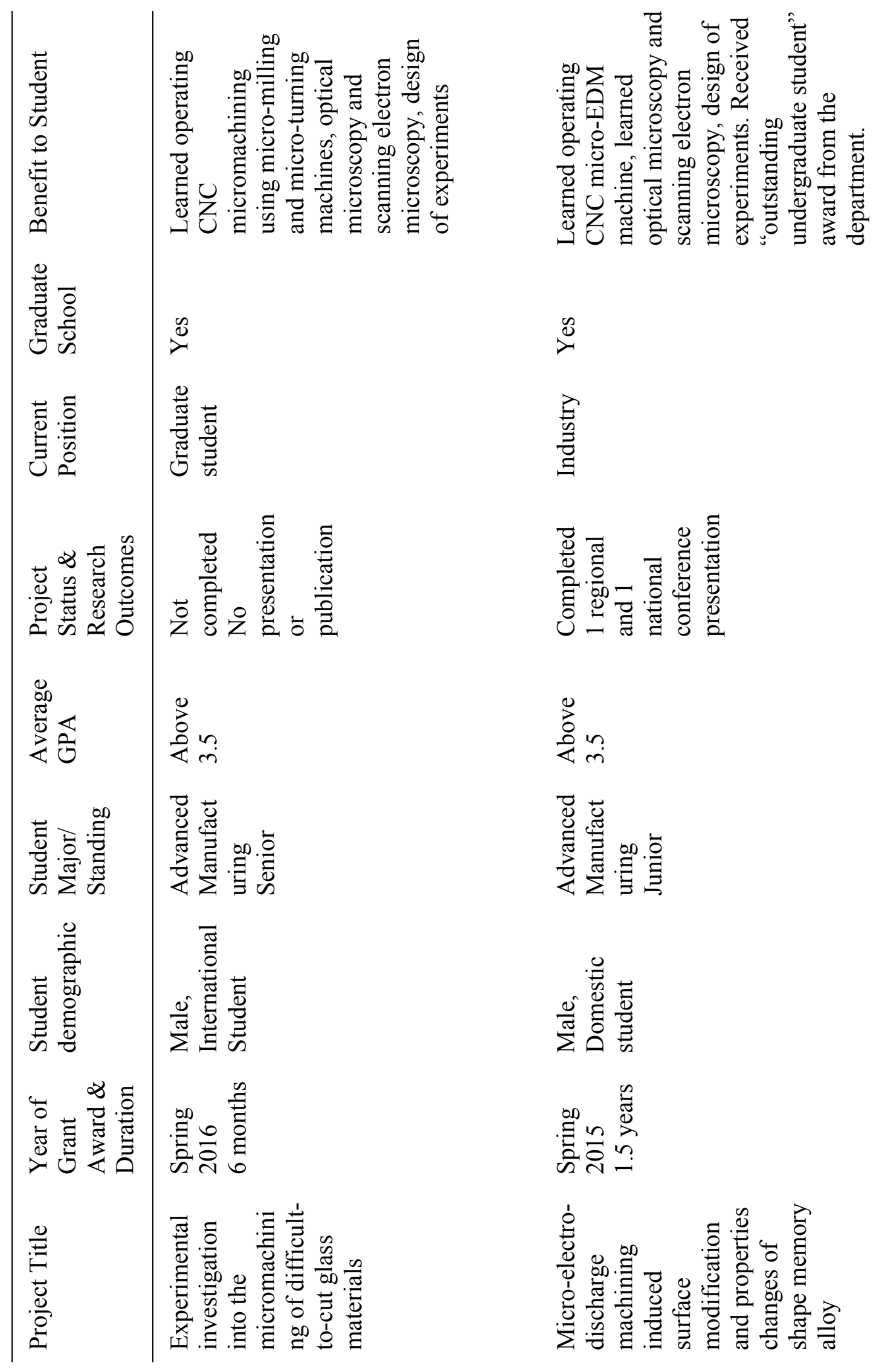




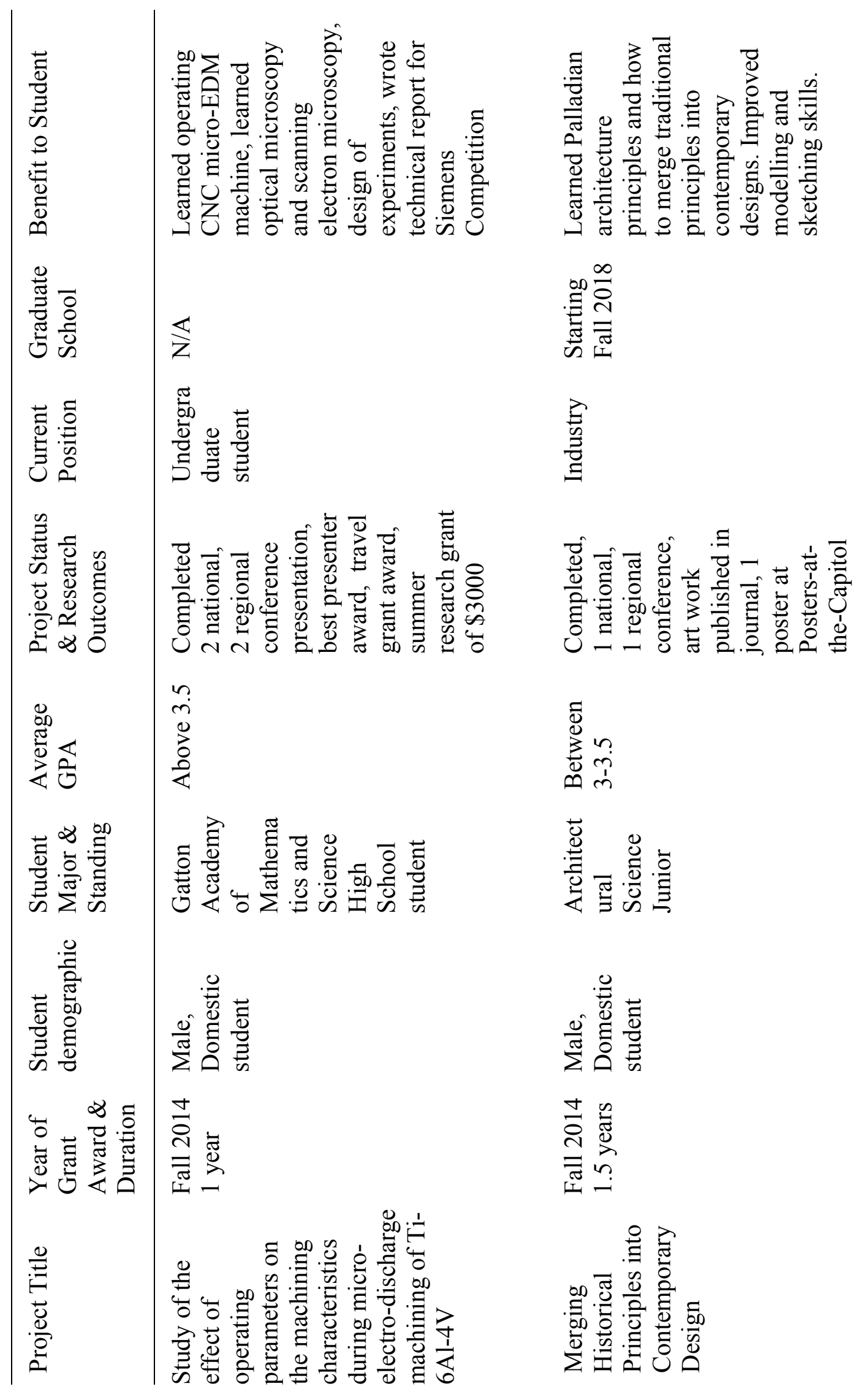




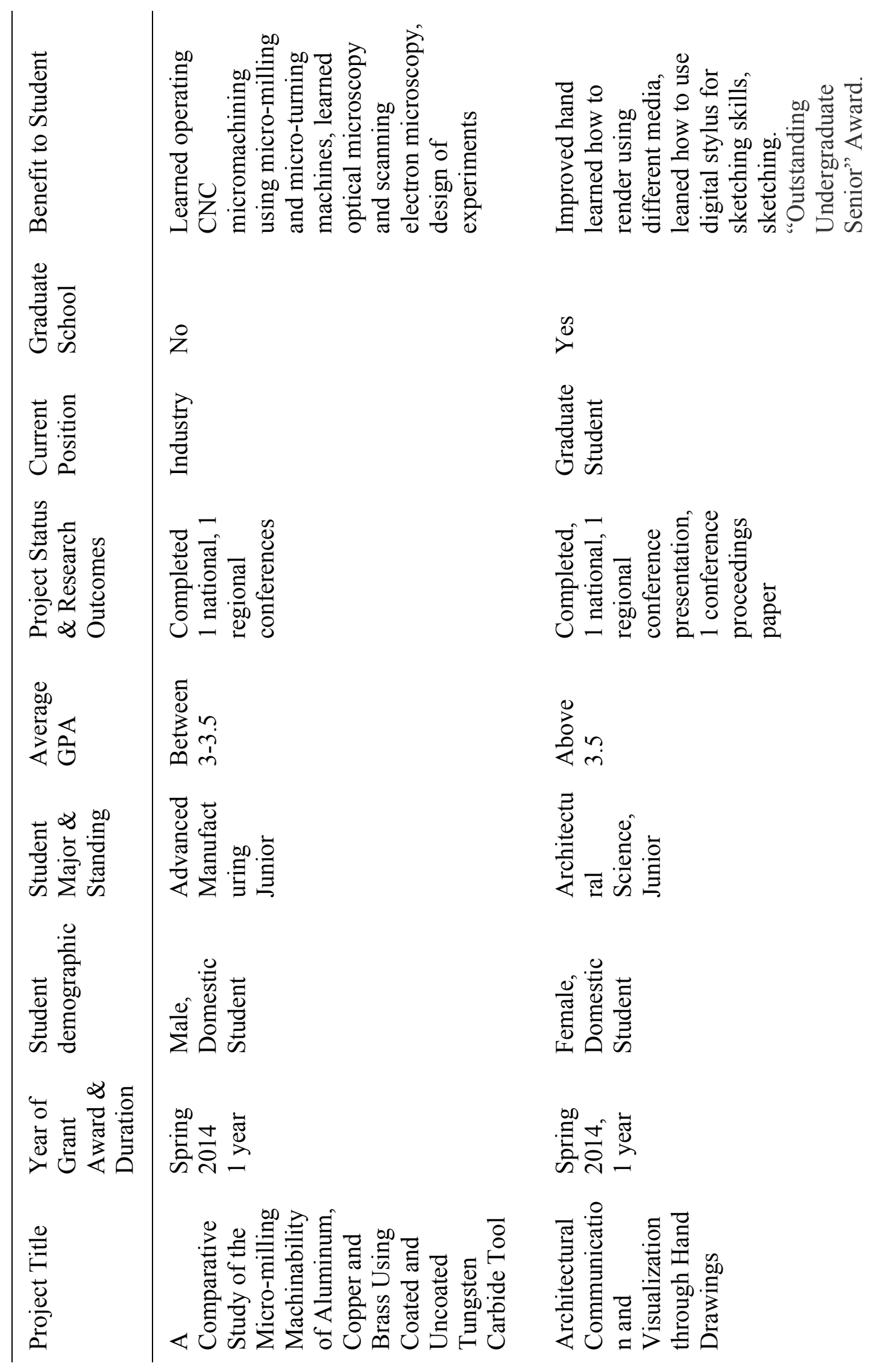




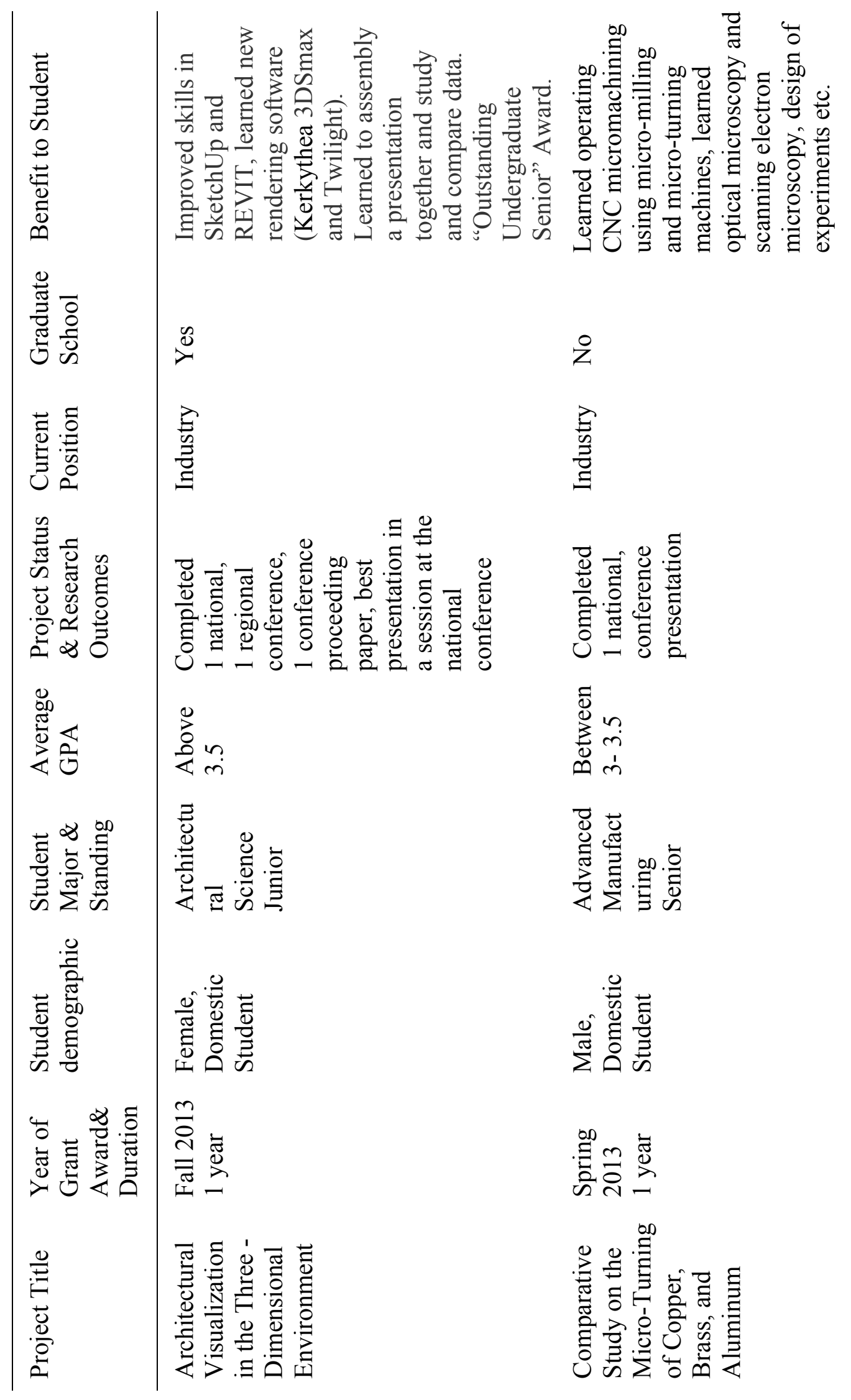




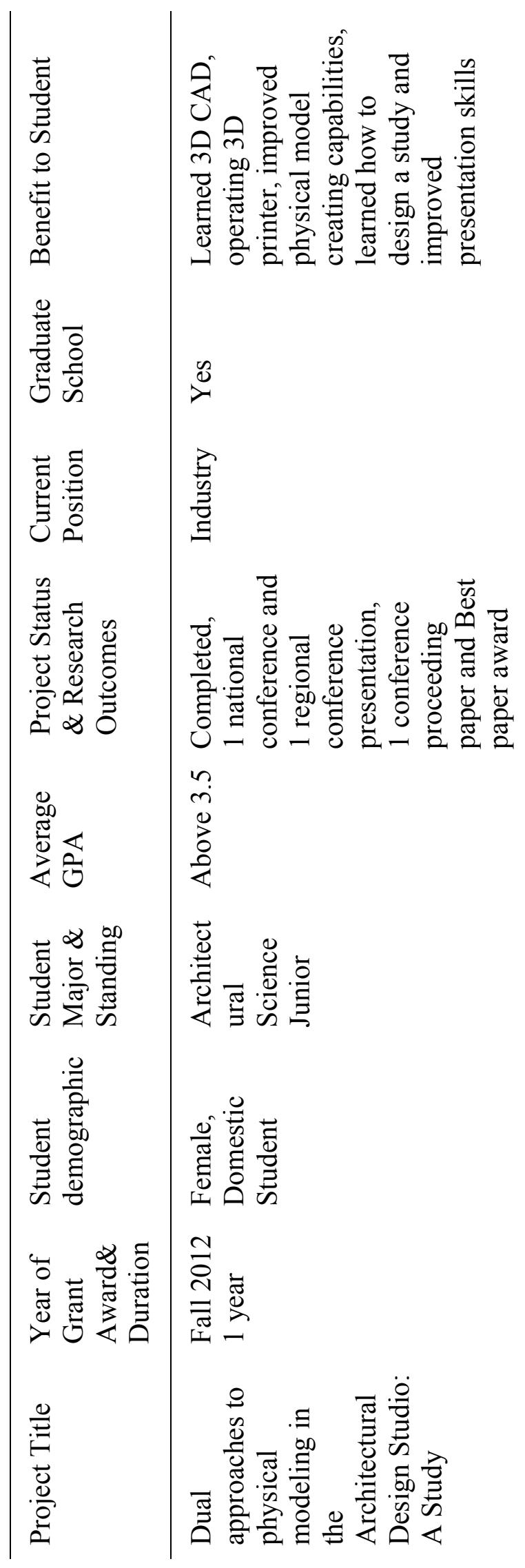

